\title{
A facile biomimetic preparation of highly stabilized silver nanoparticles derived from seed extract of Vigna radiata and evaluation of their antibacterial activity
}

\author{
Manoj Kumar Choudhary • Jyoti Kataria • \\ Swaranjit Singh Cameotra $\cdot$ Jagdish Singh
}

Received: 19 January 2015/ Accepted: 10 February 2015/Published online: 19 February 2015

(C) The Author(s) 2015. This article is published with open access at Springerlink.com

\begin{abstract}
The significant antibacterial activity of silver nanoparticles draws the major attention toward the present nanobiotechnology. Also, the use of plant material for the synthesis of metal nanoparticles is considered as a green technology. In this context, a non-toxic, eco-friendly, and cost-effective method has been developed for the synthesis of silver nanoparticles using seed extract of mung beans (Vigna radiata). The synthesized nanoparticles have been characterized by UV-visible spectroscopy (UV-Vis), Fourier transform infrared spectroscopy (FT-IR), transmission electron microscopy (TEM), atomic absorption spectroscopy (AAS), and X-ray diffraction (XRD). The UV-visible spectrum showed an absorption peak at around $440 \mathrm{~nm}$. The different types of phytochemicals present in the seed extract synergistically reduce the Ag metal ions, as each phytochemical is unique in terms of its structure and
\end{abstract}

Electronic supplementary material The online version of this article (doi:10.1007/s13204-015-0418-6) contains supplementary material, which is available to authorized users.

M. K. Choudhary $(\bowtie)$

Department of Chemistry, Guru Nanak National College,

Doraha, Punjab 141421, India

e-mail: choudhary.nrl@gmail.com

J. Kataria

Department of Chemistry, Panjab University Research Centre, Goswami Ganesh Dutta. S. D. College, Sector 32-C,

Chandigarh 160030, India

\section{S. S. Cameotra}

Institute of Microbial Technology (IMTECH-CSIR),

Sector 39-A, Chandigarh 160036, India

J. Singh

PG Department of Biotechnology, Mata Gujri College,

Fatehgarh Sahib, Punjab 140406, India antioxidant function. The colloidal silver nanoparticles were observed to be highly stable, even after 5 months. $\mathrm{XRD}$ analysis showed that the silver nanoparticles are crystalline in nature with face-centered cubic geometry and the TEM micrographs showed spherical particles with an average size of $18 \mathrm{~nm}$. Further, the antibacterial activity of silver nanoparticles was evaluated by well-diffusion method and it was observed that the biogenic silver nanoparticles have an effective antibacterial activity against Escherichia coli and Staphylococcus aureus. The outcome of this study could be useful for nanotechnologybased biomedical applications.

Keywords Biosynthesis - Silver nanoparticles · Characterization - Antibacterial activity - Vigna radiata . Surface plasmon resonance

\section{Introduction}

Nowadays, Nanotechnology is one of the most active research areas in the modern material science and technology. The development of nanotechnology creates a keen interest in the fabrication of different dimensioned nanoparticles (NPs) (Marambio-Jones and Hoek 2010). The NPs can be synthesized by various methods which include chemical (Pastoriza-Santos and Liz-Marzan 2002), photochemical (Gonzalez et al. 2009), electrochemical (Yin et al. 2003), and biological methods (Ahmad et al. 2010; Linga Rao and Savithramma 2012). The development of various new chemical or physical methods results into environmental pollution, since these chemical routes generate a large amount of hazardous by-products. Thus, there is a need for "green synthesis" which includes a clean, safe and an eco-friendly route for synthesis of NPs 
and which does not involve the use of high temperature, pressure, energy and toxic chemicals (Ahmad et al. 2010; Linga Rao et al. 2013; Jeong et al. 2005). The biogenic methods include synthesis of NPs from the bacteria, fungi and nowadays from plant extracts. The major drawbacks of using bacterial and fungal species is that these require very aseptic conditions, large manual skills to maintain cultures and thus, are much time consuming (Basavaraja et al. 2008).

Recently, plant extracts including bark, leaves, flowers and fruits have been used to synthesize the metal NPs. These biogenically synthesized NPs show more compatibility for pharmaceutical and other biomedical applications than those synthesized by chemical and physical procedures. (Crooks et al. 2001; Vijayaraghavan and Nalini 2010). Furthermore, use of plants for the synthesis of NPs does not require high energy, temperature and is cost effective and also used to scale up for large-scale synthesis (Mukunthan et al. 2011; Vankar and Shukla 2012). Among metal NPs, silver nanoparticles (AgNPs) have attracted intensive research interest because of their essential applications as catalyst, textile fabrics and antimicrobials (Sivakumar et al. 2012).

Vigna radiata commonly known as green gram or mung bean is a major edible legume seed in Asia (India, South East-Asia and East-Asia) and also eaten in Southern Europe as well as in the Southern USA. It is a rich source of minerals, vitamins and proteins with its essential amino acid profile comparable to that of other legumes (Mubarak 2005). Moreover, it also contains significant quantities of phenolic and polyphenolic compounds such as flavonoids (Sasulski and Dabrowski 1984a, b). The proteins present in the seeds are expected to self-assemble and cap the metal NPs formed in their presence and induce some shape control during metal ion reduction.

In the present paper, we report a simple, eco-friendly and cost-effective synthesis method of AgNPs at ambient conditions using seed extract of Vigna radiata as a reducing and stabilizing agent. The AgNPs synthesized by this method have the efficient antimicrobial activity against pathogenic bacteria.

\section{Materials and methods}

\section{Materials}

Silver nitrate was purchased from RENKEM, India. Vigna radiata seeds were obtained from local market of Patiala, Punjab, India. All the solutions were prepared in deionized water.
Preparation of aqueous seed extract

The seeds were washed thrice with deionised water to remove the dust and other contaminants, and dried at room temperature for $24 \mathrm{~h}$ and at $60{ }^{\circ} \mathrm{C}$ in hot air oven for $1 \mathrm{~h}$ to remove the moisture. $20 \mathrm{~g}$ of dried seed was weighed and grounded to powder by a grinding machine. Now, the powder sample was placed in $250 \mathrm{ml}$ Erlenmeyer flask containing $100 \mathrm{ml}$ deionized water. Finally, the mixture was subjected to heat at $70{ }^{\circ} \mathrm{C}$ for $1 \mathrm{~h}$. After cooling, the extract was filtered using Whatman No. 1 filter paper and stored at $4{ }^{\circ} \mathrm{C}$ for further use.

\section{Biosynthesis of silver nanoparticles}

To synthesize silver nanoparticles from Vigna radiata, $10 \mathrm{ml}$ of aqueous seed extract was carefully added to $90 \mathrm{ml}$ of $1 \mathrm{mM}$ aqueous silver nitrate solution in $250 \mathrm{ml}$ flask. The flask containing reaction mixture was incubated on a rotary shaker at $200 \mathrm{rpm}$ under dark conditions. A change in color from light yellow to reddish brown of colloidal suspension confirmed the biosynthesis of AgNPs.

\section{Characterization}

Biosynthesis of NPs by silver nitrate was monitored periodically using T-90 series double-beam ultraviolet-visible spectrophotometer (PG Instruments, England) with slit width and spectral bandwidth of 1.0 and $0.1 \mathrm{~nm}$, respectively. Concentration of silver ions was analyzed using atomic absorption spectrophotometer (AA500F-PG Instruments, England) with an operating current of $2 \mathrm{~mA}$ and a wavelength and spectral bandwidth of 328.1 and $0.2 \mathrm{~nm}$, respectively. During the course of the reaction at regular intervals, an aliquot of sample was withdrawn and centrifuged. The supernatant solution was then analyzed by AAS to detect the amount of $\mathrm{Ag}^{+}$ions. The rate of decrease in the concentration of the $\mathrm{Ag}^{+}$ions depicts the conversion of $\mathrm{Ag}^{+}$to $\mathrm{Ag}^{0}$. Analysis through XRD was carried out to confirm the crystalline nature of the AgNPs. The dried mixture of AgNPs was collected by repeated centrifugation and measurement was made on a PANalytic X'PERT-PRO X-ray spectrometer. Fourier transform infrared (FT-IR) spectrum was obtained in the range $4,000-400 \mathrm{~cm}^{-1}$ with Thermo Scientific (Nicolet-iS-50) FT-IR spectrophotometer. For transmission electron microscopy (TEM) observations, sample of biosynthesized silver nanoparticles was prepared by placing a drop of sonicated solution of colloidal suspension on carbon-coated copper grid, allowing the film on the TEM grid to stand for 2 min, removing the excess solution with blotting paper, and letting the grid dry prior to measurement. TEM 
observations were performed using a Hitachi H-7500 TEM instrument.

\section{Antimicrobial activity}

Antibacterial activity was assayed using standard well-diffusion method against human pathogenic bacteria (Escherichia coli and Staphylococcus aureus). Nutrient agar was prepared for cultivation of the bacteria. Freshgrown cultures of the microbes were spread on Petri plates containing nutrient agar for overnight and with a sterile borer; a $5 \mathrm{~mm}$ holes were punched in the medium. Varying volumes $(10,20,40,60,80$ and $100 \mu \mathrm{l})$ of solution containing NPs $(10 \mu \mathrm{g} / \mathrm{ml})$ were inoculated in these holes and plates were incubated at $37^{\circ} \mathrm{C}$ for $24 \mathrm{~h}$. Further, zone of inhibition was measured.

\section{Results and discussion}

The addition of $V$. radiata seed extract to the silver nitrate solution resulted in the change in color from light yellowish to reddish brown on incubation for $3 \mathrm{~h}$ at room temperature. The color changes in the solution were seen due to the surface plasmon vibrations of the AgNPs (Mulvaney 1996). Change in color after the reduction of silver ions $\left(\mathrm{Ag}^{+}\right)$to silver nanoparticles $\left(\mathrm{Ag}^{0}\right)$ is shown in Fig. 1b.

\section{UV-visible spectroscopy}

UV-visible spectra recorded at different time intervals for aqueous solution of silver nitrate with Vigna radiata seed extract are shown in Fig. 2a. The samples displayed an optical absorption band peak at about $440 \mathrm{~nm}$, typical of absorption for metallic Ag nanoparticles, due to the surface plasmon resonance (SPR). Effect of reaction time on the AgNPs synthesis was also studied with UV-Vis spectra and it is observed that with an increase in time the peaks become more intense. The increase in intensity is because of increase in number of nanoparticles' formation due to reduction reaction between silver ions and biomolecules presented in the aqueous solution. However, after $3 \mathrm{~h}$ of reaction time, intensity of SPR band becomes almost constant, indicating the completion of reaction. Figure $2 b$ shows the UV-Vis spectra of silver nanoparticles after storing for 5 months to test the stability of AgNPs. It has been observed that the absorption peak shifts slightly, as compared to $3 \mathrm{~h}$ absorption peak, without a significant change in color. This indicates the stability of AgNPs over a period of time.

\section{Atomic absorption spectroscopy}

Atomic absorption spectroscopy (AAS) analysis was carried out to analyze the $\mathrm{Ag}^{+}$ion concentration, which showed the conversion of $\mathrm{Ag}^{+}$ions into $\mathrm{Ag}^{0}$ nanoparticles. Initially, a standard solution of $10 \mathrm{ppm}$ of $\mathrm{AgNO}_{3}$ was prepared and analyzed with AAS at 0 min. The $\mathrm{Ag}^{+}$ion concentration in the solution was monitored at different time intervals, after adding Vigna radiata seed extract. For each sample, at least five replicates were performed and using linear regression equation (see supplementary material) concentration of silver was determined. Figure 3 shows the rate of decrease in the concentration of the $\mathrm{Ag}^{+}$ ions, which depicts the conversion of $\mathrm{Ag}^{+}$to $\mathrm{Ag}^{0}$. The results confirmed complete conversion of $\mathrm{Ag}^{+}$ions into $\mathrm{Ag}^{0}$ nanoparticles in $3 \mathrm{~h}$ of reaction time.

\section{FT-IR spectroscopy}

The FT-IR spectrum of biosynthesized silver nanoparticles depicted in Fig. 4 showed peaks at 3212.60, 2915.06, 2108.69, 1628.85, 1513.28, 1225.99, and $1016.80 \mathrm{~cm}^{-1}$, respectively. The peak at $3212.60 \mathrm{~cm}^{-1}$ is assigned to $\mathrm{N}-\mathrm{H}$ stretching vibrations of the secondary amide and bonded hydroxyl $(-\mathrm{OH})$ group. The peak at $2915.06 \mathrm{~cm}^{-1}$ is due to $\mathrm{C}-\mathrm{H}$ stretching of $-\mathrm{CH}_{3}$ and $-\mathrm{CH}_{2}$ groups of the proteins and $2108.69 \mathrm{~cm}^{-1}$ corresponding to $\mathrm{N}-\mathrm{H}$ stretching or $\mathrm{C}-\mathrm{O}$ stretching vibrations. The peak at $1628.85 \mathrm{~cm}^{-1}$ corresponds to asymmetric $\mathrm{C}=\mathrm{O}$ and (or) aromatic $\mathrm{C}=\mathrm{C}$ stretching vibration. The peak at $1513.28 \mathrm{~cm}^{-1}$ corresponds
Fig. 1 a Vigna radiata seeds. b Reddish brown solution of silver nanoparticles formed after $3 \mathrm{~h}$ due to reduction of silver ions
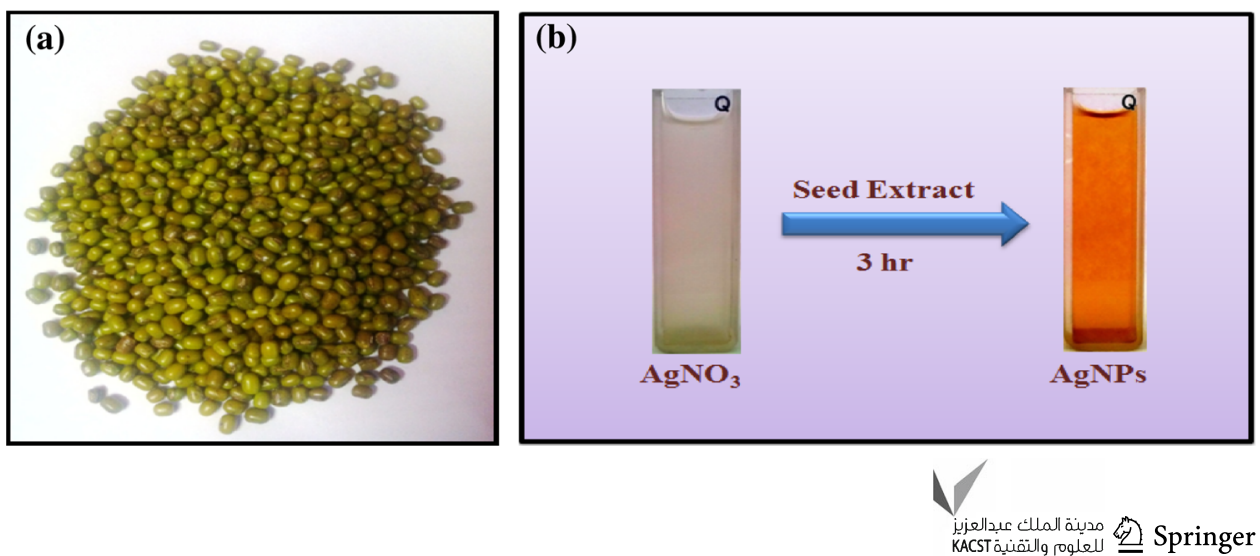

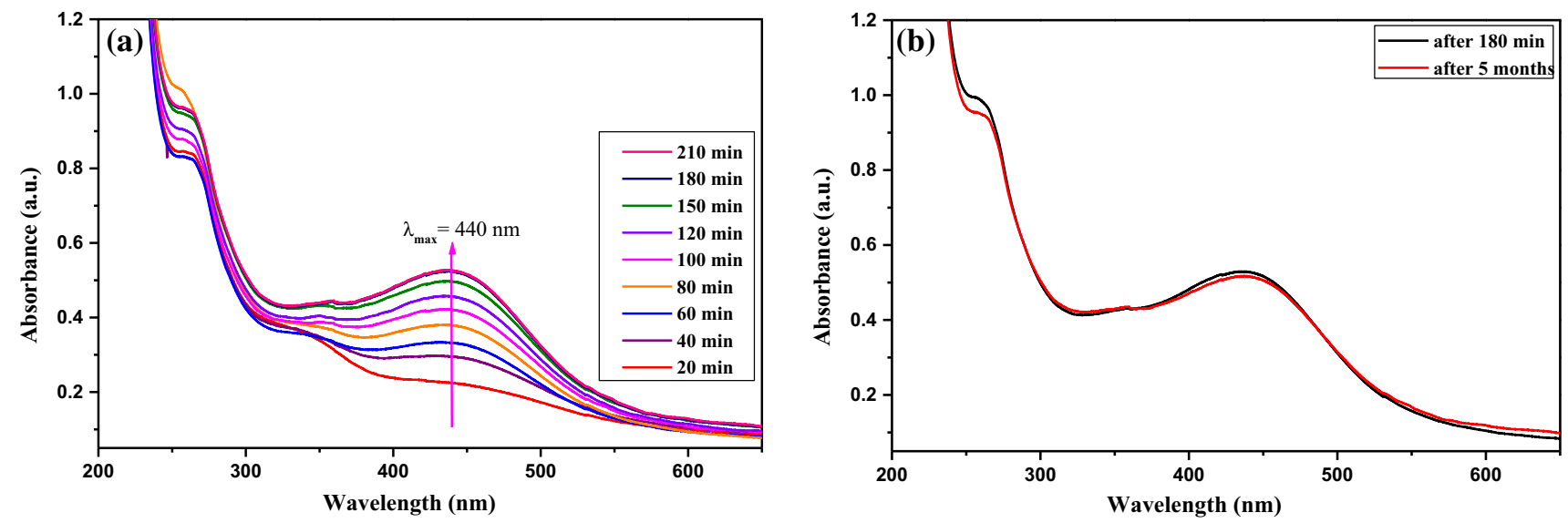

Fig. 2 a UV-visible spectra showing absorption recorded as a function of $1 \mathrm{mM}$ aqueous solution of silver nitrate with Vigna radiata seed extract as a function of time, $\mathbf{b}$ spectra recorded after 5 months

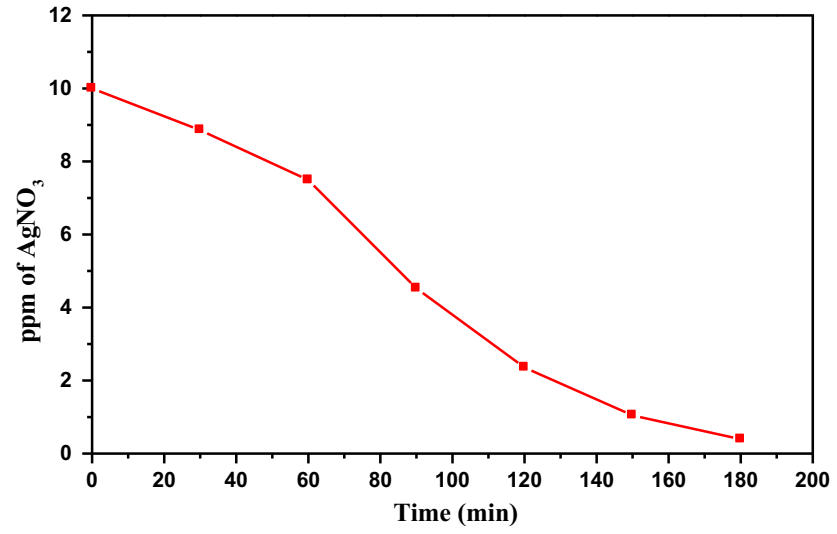

Fig. 3 AAS analysis of silver nitrate (ppm) with reaction time (min) using Vigna radiata seed extract

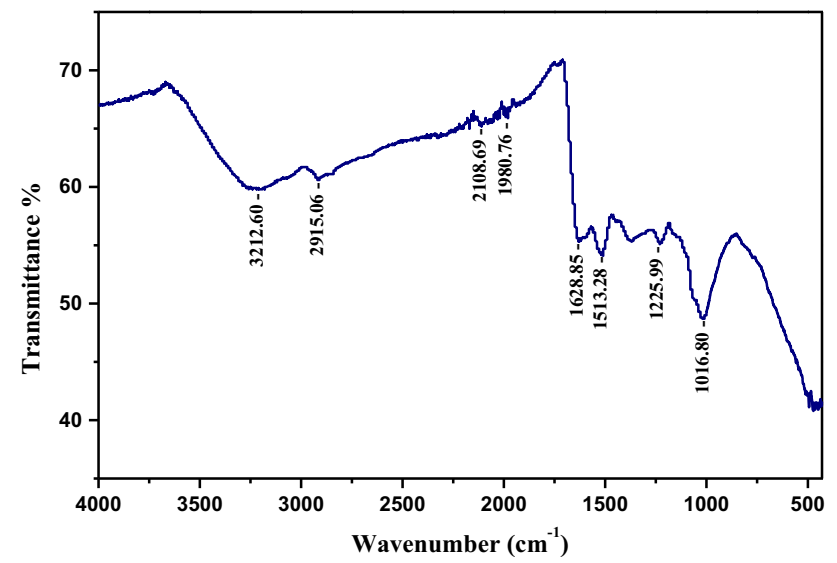

Fig. 4 FT-IR spectra of dried silver nanoparticles biosynthesized using Vigna radiata seed extract

to amide II linkage of the proteins. The peak at 1225.99 and $1016.80 \mathrm{~cm}^{-1}$ could be assigned to $\mathrm{C}-\mathrm{O}$ stretching and $\mathrm{O}-$ $\mathrm{H}$ deformation of phenolic $-\mathrm{OH}$ groups. FT-IR studies

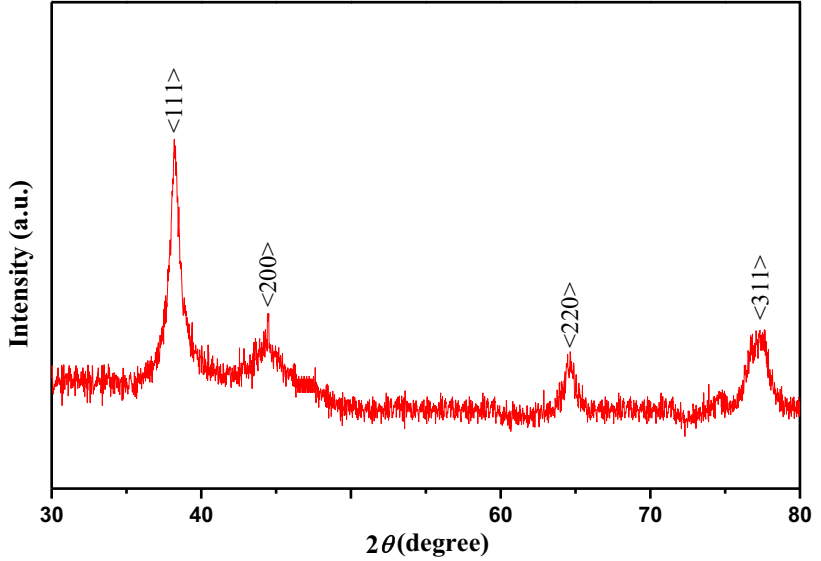

Fig. 5 XRD pattern of dried silver nanoparticles biosynthesized using Vigna radiata seed extract

suggested that phenolic compounds present in the seed extract are mainly involved in the reduction of silver ions $\left(\mathrm{Ag}^{+}\right)$into $\mathrm{AgNPs}\left(\mathrm{Ag}^{0}\right)$. Proteins could be responsible for both synthesis and stabilization of AgNPs. However, the exhaustive mechanism of the synthesis of AgNPs in this reduction reaction by phytochemical in seed extract of $V$. radiata is to be further elucidated.

\section{X-Ray diffraction}

X-ray diffraction analysis was carried out to confirm the crystalline nature of the silver nanoparticles. The XRD pattern of the biogenic silver nanoparticles (Fig. 5) showed four intense Bragg reflections that may be indexed to facecentered cubic (fcc) structure of silver. A comparison of obtained XRD spectrum with the standard (JCPDS file no. 04-0783), confirmed that the silver nanoparticles formed were in the form of crystals, as evidenced by the peaks at 
$2 \theta$ values of $38.22^{\circ}, 44.57^{\circ}, 64.73^{\circ}$, and $77.42^{\circ}$ corresponding to (111), (200), (220), and (311) planes, respectively. The unassigned reflections could be due to crystallization of bioorganic molecules that may occur on the surface of the nanoparticles. The broadening of XRD peaks around their bases indicated that the silver particles were in nanorange (Ahmad and Sharma 2012).

The average particle diameter of silver nanoparticles synthesized by present green synthesis route was calculated from the XRD pattern and using the Debye-Scherrer equation.

$D=\frac{k \lambda}{\beta \cos \theta}$,

where $D$ is the crystalline size of AgNPs, $\theta$ is the Bragg angle and $\lambda$ is the wavelength of X-ray source $(0.1541 \mathrm{~nm})$ used, $\beta$ is the breadth of the pure diffraction profile in the radians on $2 \theta$ scale and $k$ is a Scherrer constant with a value from 0.9 to 1 . The full width at half maximum (FWHM) value measured for most intense peak (111) was used with the Debye-Scherrer equation to calculate the size of the nanoparticles which came out to be $20.3 \mathrm{~nm}$.

\section{Transmission electron microscopy}

The size and shape of synthesized silver nanoparticles were examined using transmission electron microscopy (TEM) analysis. Figure 6a shows typical TEM image of biosynthesized AgNPs. It reveals that the AgNPs are well dispersed and predominantly spherical in shape, while some of the NPs were found to be oval and/or having anisotropic structures of irregular shape. Such variation in size and shape of biosynthesized NPs is common (Gangula et al. 2011). TEM analysis showed that most particles had a size of about $18 \mathrm{~nm}$. To determine the NP size distribution, more than 130 particles were analyzed using ImageJ software, and the resultant data were plotted in histogram (Fig. 6b). From this figure, it can be seen that the frequency peak lies at approximately 15-20 nm, and particles, whose sizes range from 5 to $30 \mathrm{~nm}$ account for about $95 \%$ of total particles observed.

Mung beans contain a number of essential nutrients, including proteins and carbohydrates. In addition to high protein content, mung beans also contain various enzymes and plentiful microelements. It also contains beneficial plant phytochemicals (gallic acid, $p$-hydroxybenzoic acid, protocatechuic acid, syringic acid, vanillic acid, caffeic acid and ferulic acid) which have antioxidant and anticancer activities. Based on high levels of total phenolics, mung beans show the benefits of radical scavenging activities, tyrosinase inhibition, antiproliferative and alcohol dehydrogenase activities, which could be attributed to redox property of phenolic acids. Several reports have shown close relationship between total phenolic contents and antioxidative activity (Réblová 2012; Marinova et al. 2013; Palafox-Carlos et al. 2012).

Phenolic acids due to their phenolic nucleus and a carboxylic group form a resonance-stabilized phenoxy radical which accounts for their antioxidant potential. It is generally believed that in the initial stage, oxidation of phenols leads to stable phenoxy radical formation. This radical is highly stabilized by delocalization across the whole molecule (Simic et al. 2007). It is thus possible that the phenolic acids act as a reducing agent and are oxidized by $\mathrm{AgNO}_{3}$, resulting in the formation of AgNPs (Fig. 7).

\section{Antibacterial efficacy of AgNPs}

The antibacterial activity of the AgNPs synthesized by aqueous extract of Vigna radiata seeds was studied by well-diffusion method against the Gram-negative bacteria E. coli and against the Gram-positive bacteria $S$. aureus.
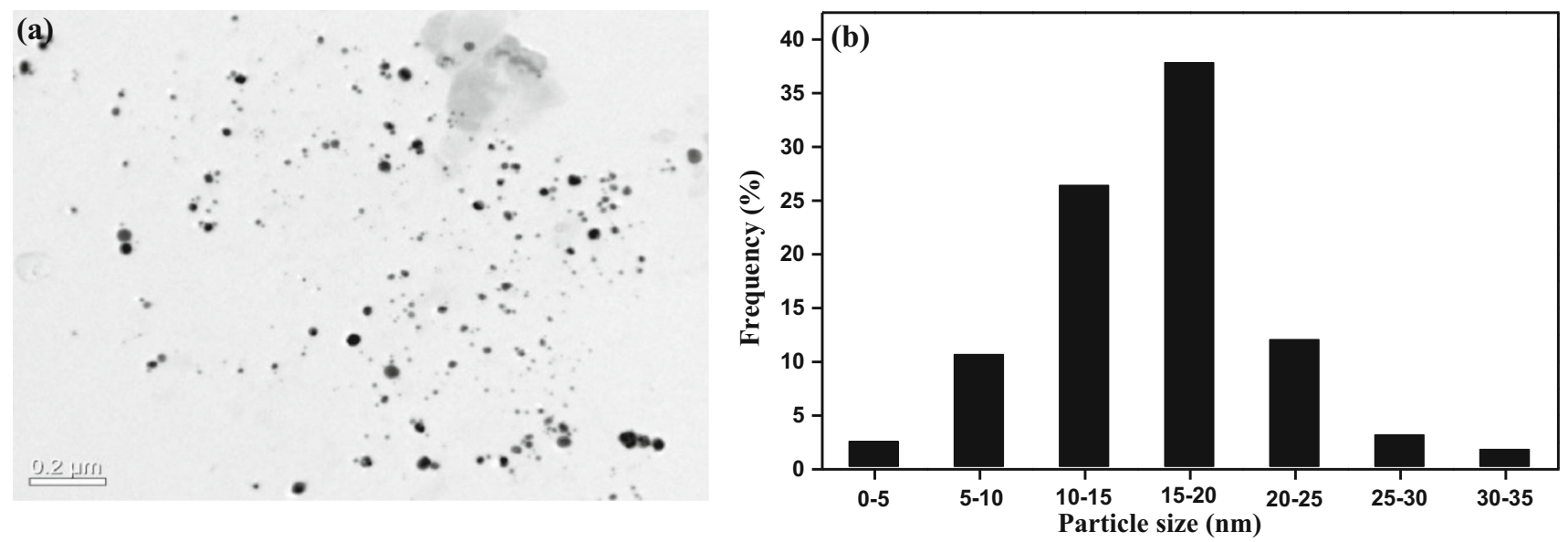

Fig. 6 a TEM image, $\mathbf{b}$ the particle size distribution of silver nanoparticles biosynthesized using Vigna radiata seed extract 


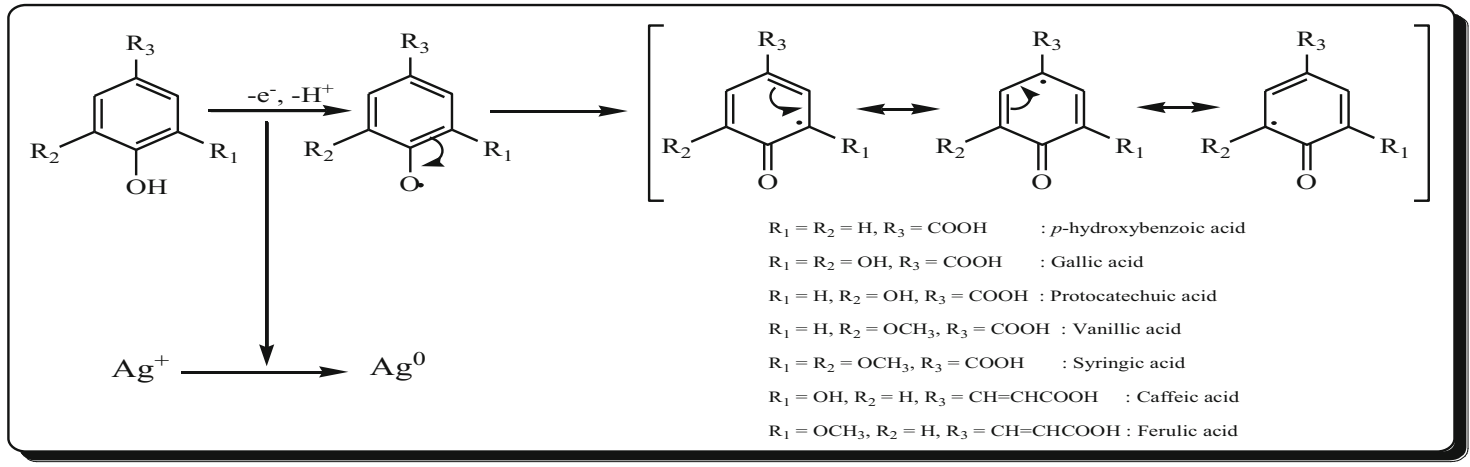

Fig. 7 Possible mechanism of reaction for the formation of silver nanoparticles
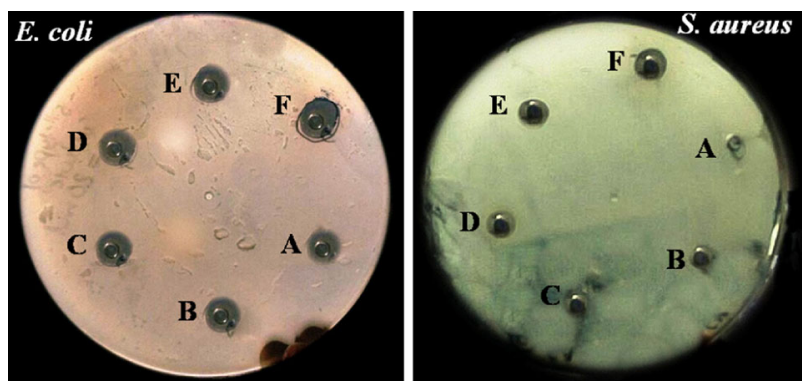

Fig. 8 Antibacterial activity of silver nanoparticles a against E. coli and $\mathbf{b} S$. aureus with varying concentration of silver nanoparticles $(A=10 \mu \mathrm{l}, \quad B=20 \mu \mathrm{l}, \quad C=40 \mu \mathrm{l}, \quad D=60 \mu \mathrm{l}, \quad E=80 \mu \mathrm{l}$ and $F=100 \mu \mathrm{l})$

Table 1 Effect of silver nanoparticles on the growth of bacterial species

\begin{tabular}{lll}
\hline Dose of AgNPs $(\mu \mathrm{l})$ & \multicolumn{2}{l}{ Zone of inhibition $(\mathrm{mm})$} \\
\cline { 2 - 3 } & E. coli & S. aureus \\
\hline 10 & 11 & - \\
20 & 13 & 9 \\
40 & 14 & 11 \\
60 & 16 & 12 \\
80 & 17 & 14 \\
100 & 20 & 16 \\
\hline
\end{tabular}

The photographs showing the antibacterial activity are shown in Fig. 8, and the value of zone of inhibition observed around the wells is given in Table 1 and Fig. 9.

It has been observed that AgNPs were more effective against E. coli than $S$. aureus. Moreover, the bactericidal activity of AgNPs was found to increase with increasing dosage. The literature reveals that the bactericidal property of AgNPs entirely depends on the particle size and dose and is more active against Gram-negative bacteria than Gram-positive bacteria (Khan et al. 2011). The probable reason might be the difference in the composition and

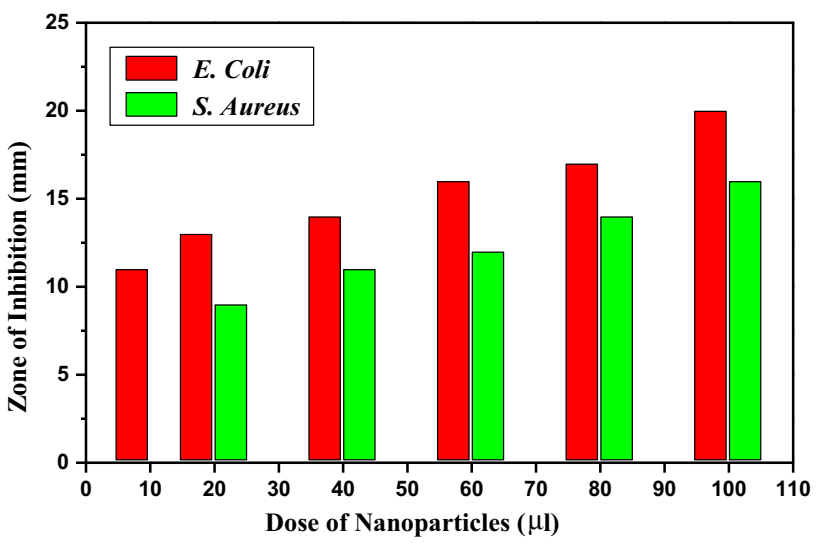

Fig. 9 Effect of silver nanoparticles on the growth of bacterial species

thickness of peptidoglycan layer in the cell wall. Grampositive bacteria possess a three-dimensional peptidoglycan layer of $\sim 80 \mathrm{~nm}$ (10 times thicker than Gram-negative bacteria), and is less susceptible to attack by AgNPs. It is believed that silver interacts with thiol groups of protein on cell membrane, which results into blocking of respiration and causing ultimate death (Sharma et al. 2009; Kaviya et al. 2011). It has also been suggested that interaction of AgNPs with cell wall increases the membrane permeability by forming pores or pits and thereby causing death of bacteria (Sondi and Salopek-Sondi 2004; Morons et al. 2005).

\section{Conclusions}

The biosynthesis of silver nanoparticles is an eco-friendly and cost-effective method. In the present study, a simple approach was attempted to synthesize silver nanoparticles at room temperature within less time span using aqueous seed extract of mung beans. The phytochemicals present in the seed extract act as an effective reducing as well as 
stabilizing agents. The synthesized nanoparticles were characterized by UV-visible spectrophotometer, FT-IR, XRD, AAS and TEM analysis. The TEM analysis revealed that the biologically synthesized silver nanoparticles were well dispersed with no agglomeration. The size of nanoparticles ranges from 5 to $30 \mathrm{~nm}$ with spherical morphology. These as-synthesized silver nanoparticles showed a broad-spectrum antibacterial activity against Gramnegative and Gram-positive bacteria. The results described in this paper will also be useful for its applications in pharmacology and medicine.

Acknowledgments The authors are grateful to the SAIF, Panjab University, Chandigarh for XRD and TEM analysis. We are also thankful to Principal and Management of GNN College, Doraha for financial support and having given feasibilities to carry out the research work.

Open Access This article is distributed under the terms of the Creative Commons Attribution License which permits any use, distribution, and reproduction in any medium, provided the original author(s) and the source are credited.

\section{References}

Ahmad N, Sharma S (2012) Green synthesis of silver nanoparticles using extracts of Ananas comosus. Green Sustain Chem 2:141-147

Ahmad N, Sharma S, Alam MK, Singh VN, Shamsi SF, Mehta BR, Fatma A (2010) Rapid synthesis of silver nanoparticles using dried medicinal plant of basil. Colloids Surf B Biointerfaces $81: 81-86$

Basavaraja S, Balaji DF, Lagashetty A, Rajasab AH, Venkataraman A (2008) Extracellular biosynthesis of silver nanoparticles using the fungus Fusarium semitectum. Mater Res Bull 43:1164-1170

Crooks RM, Zhao M, Sun L, Chechik V, Yeung LK (2001) Dendrimer-encapsulated metal nanoparticles: synthesis, characterization and application to catalysis. Acc Chem Res 34(3):181-190

Gangula A, Podila R, Ramakrishna M, Karanam L, Janardhana C, Rao AM (2011) Catalytic reduction of 4-nitrophenol using biogenic gold and silver nanoparticles derived from Breynia rhamnoides. Langmuir 27:15268-15274

Gonzalez CM, Liu Y, Scaiano JC (2009) Photochemical strategies for the facile synthesis of gold-silver alloy and core-shell bimetallic nanoparticles. J Phys Chem C 113(27):11861-11867

Jeong SH, Yeo SY, Yi SC (2005) The effect of filler particle size on the antibacterial properties of compounded polymer/silver fibers. J Mater Sci 40(20):5407-5411

Kaviya S, Santhanalakshmi J, Viswanathan B (2011) Green synthesis of silver nanoparticles using Polyalthia longifolia leaf extract along with D-Sorbitol: study of antibacterial activity. J Nanotechnol. doi:10.1155/2011/152970

Khan SS, Mukherjee A, Chandrasekaran N (2011) Studies on interaction of colloidal silver nanoparticles (SNPs) with five different bacterial species. Colloids Surf B Biointerfaces 87(1):129-138
Linga Rao M, Savithramma N (2012) Antimicrobial activity of silver nanoparticles synthesized by using stem extract of Svensonia hyderobadensis (Walp.) Mold — a rare medicinal plant. Res Biotechnol 3:41-47

Linga Rao M, Bhumi G, Savithramma N (2013) Green synthesize of silver nanoparticles by using Allamanda cathartica L. leaf extract and evaluation of their antimicrobial activity. Int J Pharm Sci Nanotechnol 6(4):2260-2268

Marambio-Jones C, Hoek EVM (2010) A review of the antibacterial effects of silver nanomaterials and potential implications for human health and the environment. J Nanopart Res 12(5):1531-1551

Marinova E, Georgiev L, Totseva I, Seizova K, Milkova T (2013) Antioxidant activity and mechanism of action of some synthesised phenolic acid amides of aromatic amines. Czech J Food Sci 31(1):5-13

Morons JR, Elechiguerra JL, Camacho A, Holt K, Kouri JB, Ramirez JT, Yacama JM (2005) The bactericidal effect of silver nanoparticles. Nanotechnology 16:2346-2353

Mubarak AE (2005) Nutritional composition and antinutritional factors of mung bean seeds (Phaseolus aureus) as affected by some home traditional processes. Food Chem 89:489-495

Mukunthan KS, Elumalai EK, Patel TN, Murthy VR (2011) Catharanthus roseus: a natural source for the synthesis of silver nanoparticles. Asian Pac J Trop Biomed 1:270A-274A

Mulvaney P (1996) Surface plasmon spectroscopy of nanosized metal particles. Langmuir 12:788-800

Palafox-Carlos H, Gil-Chávez J, Sotelo-Mundo RR, Namiesnik J, Gorinstein S, González-Aguilar GA (2012) Antioxidant interactions between major phenolic compounds found in 'Ataulfo' mango pulp: chlorogenic, gallic, protocatechuic and vanillic acids. Molecules 17:12657-12664

Pastoriza-Santos I, Liz-Marzan LM (2002) Formation of PVPprotected metal nanoparticles in DMF. Langmuir 18(7): 2888-2894

Réblová Z (2012) Effect of temperature on the antioxidant activity of phenolic acids. Czech J Food Sci 30(2):171-177

Sasulski FW, Dabrowski KJ (1984a) Composition of free and hydrolysable phenolic acids in defatted flours of ten oilseeds. J Agri Food Chem 32:128-130

Sasulski FW, Dabrowski KJ (1984b) Composition of free and hydrolysable phenolic acids in the flours and hulls of ten legume species. J Agri Food Chem 32:131-133

Sharma VK, Yngard RA, Lin Y (2009) Silver nanoparticles: green synthesis and their antimicrobial activities. Adv Colloid Interface Sci 145(1-2):83-96

Simić A, Manojlović D, Šegan D, Todorović M (2007) Electrochemical behavior and antioxidant and prooxidant activity of natural phenolics. Molecules 12:2327-2340

Sivakumar P, Nethradevi C, Renganathan S (2012) Synthesis of silver nanoparticles using Lantana camara fruit extract and its effect on pathogens. Asian J Pharm Clin Res 5(3):97-101

Sondi I, Salopek-Sondi B (2004) Silver nanoparticles as antimicrobial agent: a case study on $E$. coli as a model for Gram negative bacteria. J Colloid Interface Sci 275(1):177-182

Vankar PS, Shukla D (2012) Biosynthesis of silver nanoparticles using lemon leaves extract and its applications for antimicrobial finish on fabric. Appl Nanosci 2(2):163-168

Vijayaraghavan K, Nalini SPK (2010) Biotemplates in the green synthesis of silver nanoparticles. Biotechnol J 5(10):1098-1110

Yin B, Ma H, Wang S, Chen S (2003) Electrochemical synthesis of silver nanoparticles under protection of poly ( $N$-vinyl pyrrolidone). J Phys Chem B 107(34):8898-8904 